\title{
Análisis económico de 11 predios productores de leche y carne en la Región de Los Ríos, Chile
}

\author{
Economic analysis of 11 estates producing milk and meet in the Los Ríos Region, \\ Chile
}

\author{
Juan Lerdon $^{1 *}$, Diego Bentjerodt ${ }^{1}$,Bernardo Carrillo ${ }^{2}$, Víctor Moreira ${ }^{1}$
}

\section{RESUMEN}

Este trabajo se llevó a cabo con datos contables elaborados por medio del software CONGA, diseñado por investigadores del Instituto de Economía Agraria de la Universidad Austral de Chile, con fines de planificar y controlar la gestión de empresas agrícolas. Se establecen las estructuras de costos e ingresos de los productores para determinar las actividades con mayor incidencia en el resultado de cada explotación. Paralelamente, se determinaron, mediante los presupuestos técnico-económicos, indicadores de rentabilidad, liquidez y solvencia. Las principales conclusiones obtenidas señalan que la mayor parte de los productores genera márgenes totales positivos, siendo estos suficientes para cubrir los costos de estructura, cancelar impuestos e intereses de créditos recibidos. Los costos con mayor incidencia en los predios analizados están representados por la reposición de animales, alimentación del ganado, salarios por mano de obra ocasional y permanente y los costos de fertilización y enmiendas, los que se asemejan a otros estudios realizados anteriormente. Por otra parte, los ítems de ingresos más importantes están vinculados a la comercialización de leche, producción y venta de vaquillas, terneros y novillos. En general los productores generan rentabilidades positivas (más del $80 \%$ de los productores) tanto del capital total como del capital propio, existiendo variación entre ambas debido a que algunos necesitan de capital externo para financiar sus actividades.

Palabras clave: análisis económico, estudio de casos, producción de leche y carne.

\section{ABSTRACT}

The accounting data used in the analysis was obtained through CONGA, software designed by researchers in the Institute of Agricultural Economy of the Austral University of Chile. The aim was to be able to plan and control the management of farming businesses. Furthermore, structures of costs and income to producers were established in order to identify the activities with most relevance in the final result of each exploitation. Parallel to this, technical and financial budgets were used to determine the principal indicators, such as profitability, liquidity, solvency and financial autonomy. The main conclusions obtained from the study indicate that the majority of these producers generate positive total profit margins, with many of them being able to cover structural costs as well as paying for the interest on loans received. The costs that had a major impact on the rural properties analyzed were animal replacement, cattle feeding, part-time and full-time labour, and the costs of fertilization and repairs, all of which appear to be similar to other studies carried out in the past. On the other hand, the main items regarding income are linked to the commercialization of milk, and the production and sale of heifers, calves and bullocks. Generally speaking, producers generate positive profit margins (over $80 \%$ of producers), both on the total capital investment and on their own capital, with variations between one and the other due to the fact that some producers require external capital to finance their activities.

Key words: economic analysis, case study, milk and meat production.

\section{Introducción}

Un estudio financiero es aquel realizado a partir de información contable, mediante datos, indicadores y razones financieras de una explotación o empresa. La contabilidad manifiesta y refleja la situación actual económico-financiera del rubro, por lo que es necesario analizarla para poder entender los comportamientos de los recursos en la empresa (Lerdon, 2012).

Según Lerdon (2012), existen varios tipos de indicadores, dentro de los cuales están los

1 Instituto de Economía Agraria, Facultad de Ciencias Agrarias, Universidad Austral de Chile. Casilla 567, Valdivia, Chile.

2 Instituto de Ciencia y Tecnología de los Alimentos, Facultad de Ciencias Agrarias, Universidad Austral de Chile. Casilla 567, Valdivia, Chile.

* Autor para correspondencia jlerdon@uach.cl 
económicos, referidos principalmente a la rentabilidad de los activos, y por otro lado, los financieros, referidos a la solvencia y liquidez de la empresa.

Lerdon (2012) agrega que un análisis financiero es necesario para realizar un diagnóstico de los sucesos negativos o positivos ocurridos a lo largo de un periodo económico, en particular de aquellos que pudiesen tener consecuencias negativas en el estado económico financiero de una explotación. Respecto de la localización del estudio, la XIV Región de Los Ríos posee las condiciones edafoclimáticas para el manejo de praderas y la producción de estas, que es constituyente en gran porcentaje de la dieta en la alimentación bovina. Es por esto que se cuenta con escenarios adecuados para la producción de carne y leche (López et al.). Para este estudio se han considerado 11 productores del rubro carne y leche en la región, quienes forman un Grupo de Transferencia Tecnológica. El Instituto de Investigaciones Agropecuarias (INIA) señala que los Grupos de Transferencia Tecnológica (GTT) son una eficaz herramienta de transferencia que ha privilegiado el gobierno, con propósitos de aumentar la productividad y rentabilidad de empresas agropecuarias. Está conformado por grupos de agricultores con productividades similares, tamaño de predio, rubro, región productiva y que se reúnen periódicamente para compartir e intercambiar ideas, sistemas de trabajo y conocimientos de aspectos económicos. Estos grupos se constituyen por 10-15 agricultores, los cuales trabajan sobre una base elaborada por expertos de INIA, que posee planificaciones anuales, administrado por el guía del grupo, principal persona motivadora para lograr las metas preestablecidas. Desde los comienzos de estos trabajos en 1980, los Grupos de Transferencia Tecnológica han aportado un notable incremento en la agricultura y ganadería del país. Además, se han aumentado los niveles productivos en distintos rubros y a gran escala (INIA, 2013). El rubro de producción de carne está en crecimiento, donde influyen varios factores y organismos, dentro de los cuales están los GTT, que cada año han ayudado y contribuido en el aumento de la producción de carne y leche (FAO, 2012).

En cuanto a la producción de carne bovina en Chile, se reporta que en el 2014 el país alcanzó 205 mil toneladas, lo que significa un aumento de $8,7 \%$ comparado con el año anterior (ODEPA, 2015a). En relación con el consumo de carne por habitante en Chile, el Ministerio de Agricultura señala que en
2015, alcanzó 87,3 kilos. Esta cifra se divide en las distintas carnes que consumen los chilenos, siendo la carne de ave la que tiene un mayor consumo con 37,5 kilos por habitante al año (43\%). Seguido se encuentra la carne de vacuno con 25,3 kilos por habitante al año (29\%), luego la carne de cerdo con 23,8 kilos $(27,3 \%)$. Cabe destacar que del total de consumo de carne bovina en Chile, el $50 \%$ es producto importado (ODEPA, 2015a). Existen estudios que señalan que la producción nacional de carne bovina crecerá levemente en 2015, proveído por el aumento en las faenas de vacas y vaquillas, debido a la gran sequía del comienzo del año 2015. En Europa se observa una caída superior al $1 \%$ en la producción de carne bovina por mayores costos de los insumos y menores subvenciones gubernamentales en algunos países. En la última década, la producción europea de carne bovina acumula una caída del $7 \%$. A partir de esto se destaca en el artículo que Chile y Argentina seguirán recuperándose del descenso productivo que se originó en el periodo 2010-2011 (Instituto de promoción de la carne vacuna en Argentina, IPCVA, 2013). Según ODEPA (2015b), las plantas procesadoras de leche a nivel nacional habían recibido en 2014 un total de 2.149 millones de litros, volumen que no muestra variación significativa respecto del año anterior. El $50 \%$ de la recepción total en el 2014 se estableció en la Región de Los Lagos, siendo esta la región con mayor producción de leche en el sur de Chile. La Región de Los Ríos, por su parte, aumentó su producción en el 2014 en 0,4\% en comparación al año anterior, debido principalmente al aumento en el número de vacas. Además, este incremento se debió a condiciones meteorológicas favorables en estaciones de primavera, con abundantes días de sol y lluvias ocasionales, provocando un aumento en la producción de praderas disponibles para pastoreo y conservación de forrajes para meses de escasez. El consumo de leche bovina en el mundo aumentó el 2010 respecto del 2009 en 600 gramos per cápita al año. El 2010 el consumo total en promedio fue de 104,1 kilogramos anuales per cápita. Las cifras más elevadas de consumo por habitante se encuentran en los países desarrollados, con un total de 244 kilogramos. Por otro lado, en países subdesarrollados el consumo de leche son 67 kilogramos aproximadamente per cápita (FAO, 2012). FAO (2012) también señala que el consumo en Chile fluctúa entre los 120 y 130 litros per cápita al año, valor inferior a los 160 litros recomendados por la OMS (Organización Mundial de la Salud). 
En consideración a lo anterior y con el propósito de analizar y mejorar las producciones y técnicas de los procesos productivos, se realizó un estudio económico de 11 explotaciones de leche y carne en la Región de Los Ríos, tomando una base de datos contables del ejercicio agrícola del 1 de mayo de 2012 al 30 de abril 2013, correspondiendo a un estudio de casos.

\section{Materiales y métodos}

\section{Sitio de estudio}

El estudio se realizó en 11 predios localizados en la XIV Región de Los Ríos, los que fueron escogidos bajo ciertas condiciones, como: tener rubros en común, localizarse dentro de la Región de Los Ríos, presentar interés por conformar un GTT, tener un nivel bajo en adopción de tecnologías de información y comunicación y ser pequeños y medianos productores. Los 11 productores seleccionados se ubican en las coordenadas de los 40 grados de latitud sur y 72 grados de longitud oeste. Un $64 \%$ de ellos pertenecen a la comuna de Paillaco, un 27\% a la comuna de Futrono y un 9\%, equivalente a la comuna de Río Bueno.

\section{Obtención de la información}

La información contable del estudio se obtuvo del Instituto de Economía Agraria de la Universidad Austral de Chile, a partir de una base de datos del proyecto Innova Chile $N^{\circ} 11$ PDT-11958. Dichos datos fueron recopilados directamente de los 11 predios en estudio por los profesionales de terreno del proyecto. Mediante encuestas y por planillas Excel se establecieron los presupuestos por rubro de cada predio, con la ayuda de los propietarios o administradores. Posterior a esto se utilizó el software CONGA para almacenar y procesar los datos y obtener los indicadores económicos y financieros requeridos.

\section{Método de trabajo}

Los datos obtenidos a partir del software CONGA fueron ordenados y analizados, de tal manera de entregar al productor un resultado confiable y ordenado de sus actividades y cumplir con los objetivos del estudio. El análisis consistió en un diagnóstico de las explotaciones que conforman el GTT, denominado San Antonio, y de sus actividades o rubros. A partir de este diagnóstico técnico-económico se tuvo una visión amplia de los movimientos contables realizados en la temporada 2012-2013 que constituyen la base de los resultados del estudio, a partir de los cuales es posible visualizar los factores que explican la situación productiva actual y eficiencia económica de cada predio.

\section{Ubicación geográfica}

En la Figura 1 de la Región de los Ríos se representa la ubicación geográfica de cada explotación, según coordenadas medidas en grados, minutos y segundos, consultadas en el programa computacional Google Earth.

\section{Variables del estudio}

Este estudio consideró tres tipos de variables:

- Productivas: parámetros de espacio físico, total de superficie, cabezas de ganado, ingresos $\mathrm{y}$ costos.

- Económico-financieras: indicadores de liquidez, solvencia, rentabilidad, entre otros.

- Sociales: edad y nivel de estudios de los productores.

\section{Resultados y Discusión}

\section{Descripción general de los productores}

Los predios que conforman el Grupo de Transferencia Tecnológica pertenecen a pequeños y medianos productores que viven en las comunas de Paillaco, Futrono y Río Bueno. Ellos están vinculados con diversos programas de desarrollo $\mathrm{y}$ fomento implementados por INDAP, CORFO y la Universidad Austral de Chile. Estos productores se caracterizan por tener un rubro en común, que es la producción de carne, teniendo además otras actividades, como producción de leche, carne ovina, frambuesas, cereales, prestación de servicios.

\section{Variables productivas}

Número de cabezas por rubro

En la Tabla 1 se muestra la cantidad de cabezas de ganado por rubro. De los siete productores que tienen rubro lechero, solo el productor 4 sobrepasa 


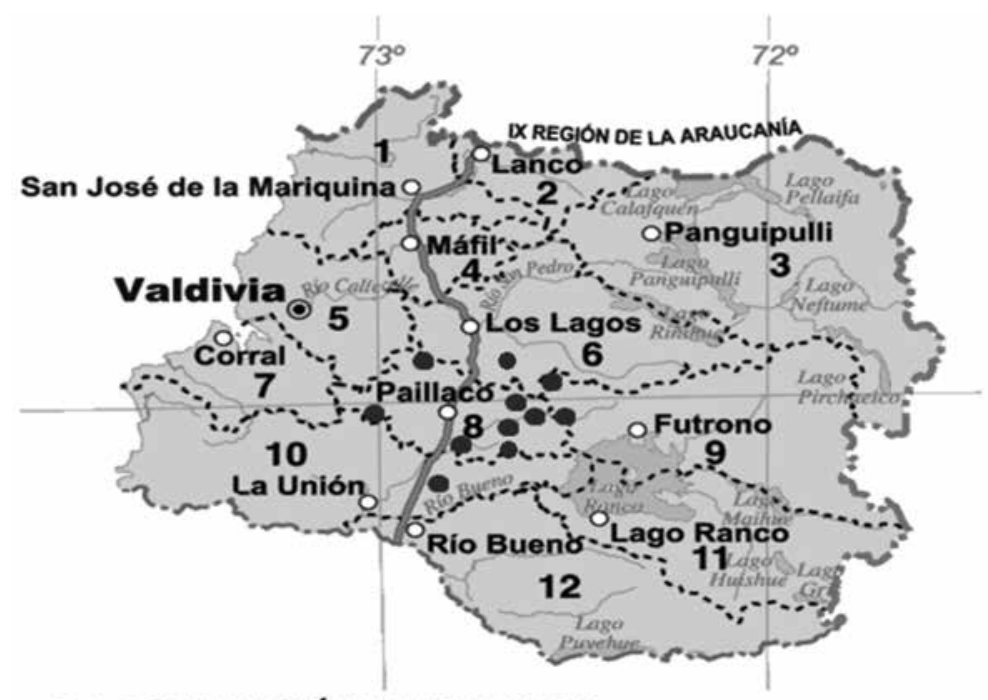

- LOCALIZACIÓN DE PREDIOS

Figura 1. Ubicación geográfica de las explotaciones en estudio.

Tabla 1. Número de cabezas de ganado por rubro.

\begin{tabular}{lccc}
\hline Productor & Lechería & Crianza terneros & Crianza vaquillas \\
\hline 1 & 53 & 90 & 70 \\
2 & 81 & 150 & 62 \\
3 & 12 & 11 & 59 \\
4 & 110 & 77 & 126 \\
5 & & 215 & 48 \\
6 & & 12 & 54 \\
7 & & 45 & 5 \\
8 & 98 & 125 & 88 \\
9 & & 28 & 30 \\
10 & 79 & 143 & 20 \\
TOTAL & 43 & 51 & 562 \\
PROMEDIO & 476 & 947 & 56 \\
\hline
\end{tabular}

las 100 cabezas de ganado. El productor 10 posee el mayor número de hectáreas y praderas, sin embargo solo tiene 79 vacas masa.

En total, los 11 productores poseen en promedio 661 cabezas de ganado, de las cuales un $23,98 \%$ son vacas productoras de leche, un $28,31 \%$ representa la crianza de vaquillas y un $47,71 \%$ la crianza de terneros.

El promedio de cabezas en el rubro crianza de terneros es de 86 animales. Los productores 1, 2, 5, 8 y 10 son aquellos que sobrepasan este promedio, siendo el productor 5 quien posee mayor número de cabezas (215). En la crianza de vaquillas se destaca el productor 4 con 126 cabezas para la reposición o venta, quien además tiene la lechería con mayor número de vacas.

\section{Número de hectáreas por productor y condición de praderas}

En la Tabla 2 se observa que el productor 10 posee la mayor superficie de terreno (190 ha) de la cual un $62,12 \%$ corresponde a praderas. Del total de superficie de praderas de los predios analizados, $71,39 \%$ son naturales y solo $21,88 \%$ son praderas mejoradas para incrementar la eficiencia productiva. 
Tabla 2. Número de hectáreas por productor y condición de praderas.

\begin{tabular}{|c|c|c|c|c|c|c|c|}
\hline Productor & $\begin{array}{l}\text { Hectáreas } \\
\text { (ha) }\end{array}$ & $\begin{array}{c}\text { Praderas } \\
\text { (ha) }\end{array}$ & $\begin{array}{l}\text { Naturales } \\
\text { (ha) }\end{array}$ & $\begin{array}{l}\text { Mejoradas } \\
\text { (ha) }\end{array}$ & $\begin{array}{l}\text { Regeneradas } \\
\text { (ha) }\end{array}$ & $\begin{array}{c}\text { Establecidas } \\
\text { (ha) }\end{array}$ & $\begin{array}{l}\text { IP } \\
\text { (ha) }\end{array}$ \\
\hline 1 & 90 & 62 & 62 & 0 & & & 28 \\
\hline 2 & 117,5 & 87 & 67 & 20 & & & 30,5 \\
\hline 3 & 39,7 & 30 & 22 & 8 & & & 9,7 \\
\hline 4 & 81 & 65 & & 58 & 7 & & 16 \\
\hline 5 & 146 & 112 & 54 & 43 & 15 & & 34 \\
\hline 6 & 37,5 & 14,1 & 14,1 & & & & 23,4 \\
\hline 7 & 42 & 40 & 40 & & & & 2 \\
\hline 8 & 140 & 50 & 40 & & & 10 & 90 \\
\hline 9 & 42 & 18 & 8 & & 10 & & 24 \\
\hline 10 & 190 & 118 & 110 & 8 & & & 72 \\
\hline 11 & 120 & 30 & 30 & & & & 90 \\
\hline TOTAL & $1.045,7$ & 626,1 & 447,1 & 137 & 32 & 10 & 419,6 \\
\hline PROMEDIO & 95,1 & 56,9 & 39,4 & 12,5 & 2,9 & 0,9 & 38,2 \\
\hline
\end{tabular}

Los productores 7 y 9 son los más pequeños, con relación a superficie, con 42 hectáreas de terreno cada uno. Sin embargo, el productor 7 tiene $95,24 \%$ de su terreno con praderas naturales y el productor 9 solo tiene $42,86 \%$ destinado a praderas. Esto puede incidir en la carga animal que soporta el predio y en los niveles de producción.

En la misma tabla, la columna IP muestra la superficie en hectáreas indirectamente productiva por explotación, destacando el productor 7 , quien tiene 42 hectáreas totales y aprovecha 95,24\% de estas, sobre la base de praderas naturales para la crianza de terneros. Los productores 8 y 11 mantienen mayor suelo indirectamente productivo (90 hectáreas). El productor 8, como se verá más adelante, arrienda 140 hectáreas, de las que 50 son praderas productivas para la alimentación de 98 vacas lecheras. El productor 11 es propietario de 120 hectáreas, de las que $25 \%$ son praderas naturales para alimentar a 43 vacas. Estos bajos porcentajes de la utilización de suelo agrícola, sea arrendado o propio, pueden atribuirse a la existencia de bosques nativos o terrenos con difícil acceso productivo.

\section{Balance inicial de los productores}

La Tabla 3 contiene las estructuras de activos y pasivos de los predios analizados, observándose que, en promedio, $88,1 \%$ de las explotaciones financia sus inversiones con capital propio o social. Según Lerdon (2012), este representa el aporte en dinero o en bienes del empresario o socios para constituir el capital económico de la empresa. Además, la estructura de este capital define la parte que el empresario o asociados tienen invertida en la empresa $\mathrm{y}$ determina las condiciones del ejercicio del poder, sirviendo de base, en el caso de sociedades, para la repartición de los resultados. Lerdon (2012) señala que muchas veces el volumen del capital propio o social es insuficiente para satisfacer las necesidades de la empresa, respecto de lo cual, en este estudio, el promedio restante del capital económico equivale a $11,9 \%$, del cual $11,7 \%$ son deudas a largo plazo. En este ítem, destaca el productor 6, a quien una institución bancaria le ha otorgado un crédito de $\$ 60.000 .000$ a largo plazo. Solo $0,2 \%$ de las empresas analizadas tiene deudas a corto plazo (productores 2 y 3), con la cooperativa lechera (\$3.300.106) e INDAP (\$ 900.000), respectivamente. Así, los capitales propios o pasivos no exigibles alcanzan un promedio de $88,1 \%$ y los exigibles (deudas de corto y largo plazo) 11,9\%.

Lerdon y Rabanal (1999), en un estudio realizado en 29 predios campesinos lecheros del área de Paillaco, encontraron promedios más altos en los pasivos no exigibles en el balance inicial de las explotaciones. En promedio 97,6\% del total corresponde a pasivos no exigibles y $2,4 \%$ del total a pasivos exigibles, cifra inferior a la obtenida en este estudio.

Por otro lado, los usos del dinero ponen en evidencia los ítems en los cuales la empresa ha invertido, contribuyendo a su desarrollo presente o futuro, los que se detallan en la Tabla 3. Las mayores inversiones están representadas por el suelo agrícola, que en promedio alcanza 47,9\% del total y fluctúa entre $79,2 \%$, que recae en el productor 10, con 190 hectáreas, y $0 \%$ (productores 
Tabla 3. Balance inicial de los productores en estudio.

\begin{tabular}{|c|c|c|c|c|c|c|c|c|c|c|c|c|c|}
\hline Balance/productor & 1 & 2 & 3 & 4 & 5 & 6 & 7 & 8 & 9 & 10 & 11 & Promedio & Rango \\
\hline \multicolumn{14}{|l|}{ pasivos } \\
\hline capital propio & 100,0 & 92,4 & 99,3 & 100,0 & 100,0 & 14,6 & 81,4 & 80,9 & 100,0 & 100,0 & 100,0 & 88,1 & $14,6-100$ \\
\hline crédito largo plazo & 0,0 & 5,9 & 0,0 & 0,0 & 0,0 & 85,4 & 18,7 & 19,1 & 0,0 & 0,0 & 0,0 & 11,7 & $0-85,4$ \\
\hline crédito corto plazo & 0,0 & 1,6 & 0,7 & 0,0 & 0,0 & 0,0 & 0,0 & 0,0 & 0,0 & 0,0 & 0,0 & 0,2 & $0-1,6$ \\
\hline total & 100,0 & 100,0 & 100,0 & 100,0 & 100,0 & 100,0 & 100,0 & 100,0 & 100,0 & 100,0 & 100,0 & 100,0 & \\
\hline \multicolumn{14}{|l|}{ activo inmovilizado } \\
\hline suelo agrícola & 0,0 & 40,1 & 49,6 & 30,6 & 63,1 & 53,4 & 74,6 & 0,0 & 71,4 & 79,2 & 65,4 & 47,9 & $0-79,2$ \\
\hline construcciones & 20,2 & 6,7 & 11,1 & 34,2 & 6,7 & 22,3 & 6,7 & 20,0 & 6,6 & 3,5 & 14,8 & 13,9 & $3,5-34,2$ \\
\hline maquinarias/equipos & 35,1 & 14,4 & 6,8 & 6,4 & 0,9 & 0,0 & 0,7 & 23,1 & 0,0 & 3,2 & 4,1 & 8,6 & $0-35,1$ \\
\hline vacas en producción & 15,4 & 11,9 & 2,8 & 5,5 & 0,0 & 0,0 & 0,6 & 20,9 & 0,0 & 6,0 & 4,7 & 6,2 & $0-20,9$ \\
\hline vacas preñadas & 6,2 & 7,7 & 0,0 & 0,0 & 0,0 & 0,0 & 0,0 & 0,0 & 0,0 & 0,0 & 1,0 & 1,4 & $0-7,7$ \\
\hline vacas secas & 0,4 & 2,5 & 0,0 & 1,7 & 3,3 & 0,0 & 0,0 & 1,4 & 0,0 & 0,0 & 0,6 & 0,9 & $0-3,3$ \\
\hline vaquillas & 1,5 & 0,4 & 1,8 & 4,8 & 0,6 & 17,5 & 2,0 & 11,6 & 9,3 & 1,3 & 1,2 & 4,7 & $0,4-17,5$ \\
\hline toros & 1,4 & 1,0 & 0,0 & 0,1 & 0,0 & 0,0 & 0,0 & 0,6 & 0,4 & 0,5 & 0,2 & 0,4 & $0-1,4$ \\
\hline bueyes & 0,0 & 0,0 & 0,0 & 0,2 & 0,0 & 1,1 & 0,0 & 0,0 & 0,0 & 0,3 & 0,6 & 0,2 & $0-1,1$ \\
\hline caballos & 0,7 & 0,0 & 0,0 & 0,0 & 0,0 & 0,0 & 0,0 & 11,1 & 0,2 & 0,0 & 0,2 & 1,1 & $0-11,1$ \\
\hline bonos o acciones & 1,9 & 5,6 & 0,0 & 13,5 & 0,0 & 0,0 & 0,0 & 0,0 & 0,0 & 0,0 & 3,5 & 2,2 & $0-13,5$ \\
\hline total inmovilizado & 82,8 & 90,4 & 72,1 & 97,0 & 74,8 & 94,3 & 84,6 & 88,6 & 87,9 & 93,9 & 96,5 & 87,5 & \\
\hline \multicolumn{14}{|l|}{ activo circulante } \\
\hline semillas & 0,1 & 0,0 & 0,0 & 0,0 & 0,2 & 0,0 & 0,0 & 4,6 & 0,3 & 0,0 & 0,0 & 0,5 & $0-4,6$ \\
\hline fertilizantes & 3,6 & 1,6 & 4,7 & 0,0 & 0,3 & 0,0 & 0,0 & 0,0 & 0,0 & 0,0 & 0,0 & 0,9 & $0-4,7$ \\
\hline agroquímicos & 0,0 & 0,0 & 0,1 & 0,0 & 0,0 & 0,0 & 0,0 & 0,0 & 0,0 & 0,0 & 0,0 & 0,0 & $0-0,1$ \\
\hline bolos & 0,0 & 1,74 & 0,0 & 0,0 & 0,0 & 0,0 & 0,0 & 0,0 & 0,0 & 0,0 & 0,0 & 0,2 & $0-1,74$ \\
\hline fardos & 0,8 & 0,0 & 0,0 & 0,1 & 0,2 & 0,0 & 0,0 & 0,3 & 0,0 & 0,0 & 0,2 & 0,2 & $0-0,8$ \\
\hline henos & 3,1 & 1,4 & 2,7 & 0,1 & 1,2 & 0,0 & 1,1 & 1,5 & 0,7 & 0,2 & 0,3 & 1,1 & $0-3,1$ \\
\hline ensilaje & 1,9 & 2,3 & 0,0 & 1,4 & 0,0 & 0,0 & 0,0 & 0,0 & 0,3 & 1,3 & 0,7 & 0,7 & $0-2,3$ \\
\hline vacas desecho & 0,0 & 0,4 & 0,0 & 0,2 & 0,2 & 0,0 & 0,0 & 0,5 & 0,0 & 0,0 & 0,0 & 0,1 & $0-0,5$ \\
\hline terneros/as leche & 6,8 & 1,8 & 0,1 & 0,6 & 0,6 & 0,7 & 3,7 & 2,7 & 1,1 & 1,6 & 0,9 & 1,9 & $0,1-6,8$ \\
\hline novillos & 0,0 & 0,1 & 0,0 & 0,0 & 13,5 & 0,0 & 9,8 & 0,2 & 1,6 & 0,7 & 0,9 & 2,4 & $0-13,5$ \\
\hline otra actividad & 0,0 & 0,0 & 9,3 & 0,2 & 2,9 & 2,1 & 0,0 & 0,0 & 8,2 & 0,0 & 0,1 & 2,1 & $0-9,3$ \\
\hline caja & 0,7 & 0,05 & 0,6 & 0,6 & 0,0 & 0,0 & 0,7 & 0,0 & 0,0 & 0,9 & 0,1 & 0,3 & $0-0,9$ \\
\hline otro banco & 0,0 & 0 & 0,0 & 0,0 & 5,2 & 0,0 & 0,0 & 0,0 & 0,0 & 0,0 & 0,2 & 0,5 & $0-5,2$ \\
\hline cuenta corriente & 0,0 & 0,2 & 10,4 & 0,0 & 0,6 & 2,9 & 0,0 & 1,6 & 0,0 & 1,3 & 0,0 & 1,6 & $0-10,4$ \\
\hline total circulante & 17,2 & 9,6 & 28,0 & 3,0 & 25,2 & 5,7 & 15,4 & 11,4 & 12,2 & 6,1 & 3,5 & 12,5 & $3,1-28,3$ \\
\hline total & 100,0 & 100,0 & 100,0 & 100,0 & 100,0 & 100,0 & 100,0 & 100,0 & 100,0 & 100,0 & 100,0 & 100,0 & \\
\hline
\end{tabular}

1 y 8), que solo arriendan terrenos para producir. El segundo ítem más alto en los usos del capital son las construcciones específicas y no específicas, que en promedio representan $13,9 \%$ del total y que varía entre $34,2 \%$ (productor 3 ) y $3,5 \%$ (productor 10). Cabe mencionar que el productor 3 invierte $\$ 13.950 .000$ en construcciones, lo que equivale a $11 \%$ de su capital total, a diferencia del productor 10 que invierte \$ 18.500 .000 , equivalente solo a un 3,5\%, ya que su capital total es mucho mayor. El tercer ítem con más relevancia corresponde a maquinarias y equipos, con un promedio de $8,6 \%$ del total, fluctuando entre $35,2 \%$ (productor 1 ) y $0 \%$ (productores 6 y 9), quienes externalizan los servicios para labores agrícolas. El cuarto ítem importante de inversiones son las vacas en producción, que en promedio representan $6,2 \%$ del total, fluctuando entre $20,9 \%$ (productor 8) con 98 cabezas en ordeña 
y $0 \%$ para productores que no poseen lechería. De esta manera, el promedio calculado en este estudio, para el activo inmovilizado y circulante, es de $87,5 \%$ y $12,5 \%$.

\section{Tamaño y propiedad del suelo}

En la Tabla 4 es posible observar que 9 de los 11 productores son propietarios de sus predios, con una superficie promedio de 81,22 hectáreas totales, destacando el productor 10 con 190 hectáreas. Cuatro productores arriendan en promedio 78,75 hectáreas, con un rango de 10 a 140 hectáreas, para establecer cultivos o aumentar su masa de ganado.

\section{Margen directo rubro de lechería}

En la Tabla 5 se observa que el rubro lechería genera márgenes directos totales que fluctúan entre $\$ 73.337 .774$ (productor 4) y $\$-5.876 .961$ (productor 3). Estas diferencias se ven reflejadas en las estructuras de ingresos y costos, así como en el número de cabezas que posee cada productor; mientras el productor 3 tiene solo 12 vacas en ordeña, el productor 4 posee 110 , generando ingresos más altos y un mayor margen.

Otro factor de esta diferencia es el destino final del producto. El productor 4 entrega su leche en una cooperativa industrial, por lo cual el precio pagado por litro es más alto, recibiendo además bonos por calidad de leche y certificación de predio libre de patologías. El productor 3 procesa su leche en su predio y el precio de venta es más bajo, además de no tener bonificaciones.

En la misma Tabla es posible observar que la suma de márgenes directos del rubro lechería de los 11 productores, es $\$ 183.754 .510$, con un total de 476 vacas en ordeña. El promedio de ingresos es de $\$ 26.250 .644$, correspondiente a 68 vacas promedio en ordeña.

Tabla 4. Propiedad del suelo de los productores.

\begin{tabular}{lccc}
\hline Productor & Suelo propio (ha) & Suelo arrendado (ha) & TOTAL \\
\hline 1 & 0 & 90 & 90 \\
2 & 42,5 & 75 & 117,5 \\
3 & 39,7 & 0 & 39,7 \\
4 & 81 & 0 & 81 \\
5 & 146 & 0 & 146 \\
6 & 37,5 & 0 & 37,5 \\
7 & 42 & 0 & 42 \\
8 & 0 & 140 & 140 \\
9 & 32 & 10 & 42 \\
10 & 190 & 0 & 190 \\
11 & 120 & 0 & 120 \\
TOTAL & 731 & 315 & 1.046 \\
PROMEDIO & 81,22 & 78,75 & 95,09 \\
\hline
\end{tabular}

Tabla 5. Margen directo rubro de lechería.

\begin{tabular}{|c|c|c|c|c|c|}
\hline Productor & $\begin{array}{c}\text { Margen directo } \\
(\$)\end{array}$ & $\begin{array}{l}\text { Número de } \\
\text { cabezas }\end{array}$ & $\begin{array}{l}\text { Tamaño del } \\
\text { predio (ha) }\end{array}$ & $\begin{array}{c}\text { Margen directo/cabeza } \\
(\$)\end{array}$ & $\begin{array}{c}\text { Margen directo/superficie } \\
\text { total (\$) }\end{array}$ \\
\hline 1 & 15.176 .381 & 53 & 90 & 286.346 & 168.626 \\
\hline 2 & 17.760 .338 & 81 & 117,5 & 219.263 & 151.152 \\
\hline 3 & -5.876 .961 & 12 & 39,7 & -489.746 & -148.034 \\
\hline 4 & 73.337 .774 & 110 & 81 & 666.707 & 905.405 \\
\hline \multicolumn{6}{|l|}{5} \\
\hline \multicolumn{6}{|l|}{6} \\
\hline \multicolumn{6}{|l|}{7} \\
\hline 8 & 25.978 .528 & 98 & 140 & 265.087 & 185.561 \\
\hline \multicolumn{6}{|l|}{9} \\
\hline 10 & 35.378 .609 & 79 & 190 & 447.830 & 186.203 \\
\hline 11 & 21.999 .841 & 43 & 120 & 511.624 & 183.332 \\
\hline TOTAL & 183.754 .510 & 476 & 778 & 1.907 .111 & 1.632 .245 \\
\hline PROMEDIO & 26.250 .644 & 68 & 111 & 272.444 & 233.178 \\
\hline
\end{tabular}


Los márgenes directos unitarios (por cabeza) presentan un promedio de $\$ 272.444$, con un rango de $-\$ 498.746$ a $\$ 666.707$, siendo los productores 4 y 11 que presentan los valores más altos. El productor 4 genera un margen por cabeza de $\$ 666.707$ con 110 cabezas. Por otro lado, el productor 11 genera un margen directo por cabeza de $\$ 511.624$, con tan solo 43 cabezas. Esta mayor productividad por cabeza se debe fundamentalmente a que el productor 11 tiene costos menores de producción por animal, empleando similares insumos y dietas que otros productores, pero con costos por unidad más bajos.

Respecto del margen directo por hectárea destinada a lechería, destaca el productor 4 con $\$ 905.405$. Este valor es el más alto de los casos analizados, correspondiendo al productor con el margen directo total más alto y a su vez el segundo más pequeño en cuanto a superficie ( 81 hectáreas). Esta situación se relaciona con un mejor aprovechamiento del terreno disponible y la presencia de praderas permanentes y de rotación de mejor calidad, en comparación con otros productores del GTT.

\section{Margen directo crianza de vaquillas}

Los márgenes para este rubro se presentan en Tabla 6 y son similares a los del rubro lechería. El productor 4 nuevamente es aquel que posee un mayor número de cabezas (126 cabezas) y genera un margen directo por animal de $\$ 111.905$. Sin embargo, el productor 8 posee 88 vaquillas y su margen directo por animal es de \$ 176.453. Esta diferencia se debe a que el productor 4 tiene costos adicionales en la dieta, incluyendo sales minerales en la alimentación, lo que podría ser considerado como positivo. Este costo es de $\$ 516.800$ para el productor 4 a diferencia del productor 8 que solo alimenta sobre la base de henos de pradera, pastoreo y bolos.

Es importante destacar que el uso de sales minerales es recomendable en la alimentación bovina, sobre todo cuando hay déficit de minerales en el suelo y se debe suplementar en la dieta. En muchas explotaciones lecheras existen problemas de deficiencia subclínica de uno o más minerales, lo que es difícil de diagnosticar (Pérez, et al., 2011). $\mathrm{El}$ productor 8 no presenta deficiencias en sus praderas y derivados de estas, por lo que no debe incluir sales minerales en la dieta de sus vaquillas, a diferencia del productor 4 , que sí incluye, lo que no significa que no sea recomendable.

Otra respuesta a esta diferencia es que el productor 4 tiene gastos más elevados en productos veterinarios (\$295.000). Los gastos en productos veterinarios para el productor 8 son de $\$ 120.000$.

\section{Margen directo crianza de terneros}

Este análisis está referido a los márgenes directos que generan los productores del GTT mediante la crianza de terneros (Tabla 7), los que fluctúan entre -\$1.736.023 y \$ 3.961.230, con un promedio de $\$ 1.402 .715$.

El productor 10 sigue teniendo el mayor número de cabezas en este rubro, así como el mayor margen directo total; sin embargo, sus altos costos se ven reflejados en un margen directo por cabeza por debajo del promedio general (\$27.701). Si se compara con el productor 11, este cría 92 terneros menos que el

Tabla 6. Margen directo crianza de vaquillas.

\begin{tabular}{|c|c|c|c|}
\hline Productor & Margen directo (\$) & Número de cabezas & Margen directo/cabeza (\$) \\
\hline 1 & 4.049 .028 & 70 & 57.843 \\
\hline 2 & 5.006 .321 & 62 & 80.747 \\
\hline 3 & 4.053 .043 & 59 & 68.696 \\
\hline 4 & 14.100 .041 & 126 & 111.905 \\
\hline \multicolumn{4}{|c|}{ 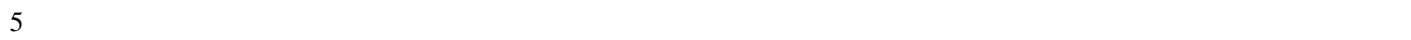 } \\
\hline \multicolumn{4}{|l|}{6} \\
\hline \multicolumn{4}{|l|}{7} \\
\hline 8 & 15.527 .833 & 88 & 176.453 \\
\hline 9 & -14.877 .580 & 30 & -495.919 \\
\hline \multicolumn{4}{|c|}{ 1.0. } \\
\hline 11 & 1.475 .978 & 20 & 73.799 \\
\hline TOTAL & 29.334 .664 & 455 & 73.523 \\
\hline PROMEDIO & 4.190 .666 & 65 & 10.503 \\
\hline
\end{tabular}


productor 10 , pero genera un margen por cabeza $\$ 182.188$ mayor. Esto se debe principalmente a que durante la crianza, el productor 10 tuvo que enfrentarse a gastos elevados en productos veterinarios, no siendo así para el productor 11.

El productor 3 genera el menor margen por cabeza con solo 11 terneros criados y costos de mantención elevados, generándose así un margen negativo de $-\$ 58.909$.

\section{Margen de gastos e ingresos generales}

El productor 2 (Tabla 8) es el único que presenta un margen positivo, entre gastos e ingresos generales. Sus mayores gastos son el salario de mano de obra permanente (\$10.368.000), las remuneraciones al administrador del predio (\$9.600.000), el combustible $(\$ 1.800 .000)$ y la electricidad $(\$ 1.800 .000)$, entre otros. No obstante, este productor, a pesar de dedicarse al rubro de carne y leche, presta servicios de maquinaria, lo que evidentemente le genera ingresos importantes en comparación al resto de los productores $(\$ 27.600 .000)$, los cuales, a solicitud del productor, fueron considerados como ingresos generales y sus costos como gastos generales.

El productor 3 también obtiene ingresos por prestación de servicios, generándole en la temporada un monto de $\$ 10.200 .000$. Sin embargo, y para esta misma temporada, el productor debió asumir gastos elevados en mantención y reparación de construcciones (\$8.000.000), lo que, sumado a los gastos fijos en remuneraciones al administrador, combustible, electricidad, teléfono, entre otros, los ingresos no alcanzan a solventar los gastos.

En general, los gastos generales, descontados los ingresos generales y expresados por hectárea, fluctúan entre $\$ 9.311$ y $-\$ 328.827$, con un promedio de $-\$ 162.609$.

Tabla 7. Margen directo crianza de terneros.

\begin{tabular}{lccc}
\hline Productor & Margen directo $(\$)$ & Número de cabezas & Margen directo/cabezas $(\$)$ \\
\hline 1 & 3.186 .305 & 90 & 35.403 \\
2 & 1.864 .213 & 114 & 16.353 \\
3 & -648.002 & 11 & -58.909 \\
4 & -1.736 .023 & 77 & -22.546 \\
5 & 2.618 .002 & 44 & 59.500 \\
6 & 1.225 .447 & 12 & 102.121 \\
7 & 1.500 .438 & 45 & 33.343 \\
8 & 1.605 .543 & 125 & 12.844 \\
9 & 114.218 & 28 & 4.079 \\
10 & 3.961 .230 & 143 & 27.701 \\
11 & 1.738 .497 & 51 & 209.889 \\
TOTAL & 15.429 .868 & 740 & 419.779 \\
PROMEDIO & 1.402 .715 & 67 & 38.162 \\
\hline
\end{tabular}

Tabla 8. Margen de gastos e ingresos generales.

\begin{tabular}{|c|c|c|c|c|c|}
\hline Productor & Total Ingreso & Total Costo & Margen Actividad & $\mathrm{Ha}$ & Margen/Ha \\
\hline 1 & 9.600 .000 & 17.256 .500 & -7.656 .500 & 90 & -85.072 \\
\hline 2 & 27.600 .000 & 26.506 .000 & 1.094 .000 & 117,5 & 9.311 \\
\hline 3 & 10.200 .000 & 15.126 .000 & -4.926 .000 & 39,7 & -124.081 \\
\hline 4 & 0 & 26.635 .000 & -26.635 .000 & 81 & -328.827 \\
\hline 5 & 0 & 9.430 .178 & -9.430 .178 & 146 & -64.590 \\
\hline 6 & 0 & 10.468 .500 & -10.468 .500 & 37,5 & -279.160 \\
\hline 7 & 0 & 11.244 .000 & -11.244 .000 & 42 & -267.714 \\
\hline 8 & 0 & 25.927 .885 & -25.927 .885 & 140 & -185.199 \\
\hline 9 & 0 & 7.230 .000 & -7.230 .000 & 42 & -172.143 \\
\hline 10 & 0 & 27.447 .000 & -27.447 .000 & 190 & -144.458 \\
\hline 11 & 0 & 17.612 .000 & -17.612 .000 & 120 & -146.767 \\
\hline TOTAL & 47.400 .000 & 194.883 .063 & -147.483 .063 & 1.046 & -1.788 .700 \\
\hline PROMEDIO & 4.309 .091 & 17.716 .642 & -13.407 .551 & 95.06363636 & -162.609 \\
\hline
\end{tabular}




\section{Margen total explotaciones}

Los márgenes totales de las explotaciones analizadas se presentan en la Tabla 9, con un promedio de $\$ 15.555 .621$ y un rango de $-\$ 7.397 .920$ a \$ 59.066.792. El mayor margen total lo presenta el productor 4 , el que tiene un mayor número de cabezas de ganado, mantiene 58 hectáreas de praderas mejoradas y regeneró otras 7 hectáreas, por lo que la alimentación del ganado es sobre la base de praderas y derivados de estas, evitando gastos de concentrados.

El productor 3, que presenta el menor margen total, es el segundo más pequeño en cuanto a superficie, y con 12 vacas en ordeña no logra cubrir los costos totales de su explotación. Tiene 39,7 hectáreas, lo que limita el crecimiento en cabezas de ganado, ya que tendría que sobrecargar el predio para aumentar su producción, o en su defecto arrendar superficie.

Al analizar los márgenes de explotación por hectárea, estos fluctúan entre -\$186.346 y \$ 729.220, observándose los mismos productores (3 y 4). Por tanto, estos valores se pueden relacionar, como se mencionó anteriormente, con la eficiencia técnica de producción, los costos de alimentación y disponibilidad de suelo para producir forraje.

\section{Estructura de costos}

En la Tabla 10 se puede apreciar que en promedio, el costo de la reposición de animales es el ítem con mayor incidencia en los costos totales $(38,30 \%)$. Con un rango de $18,54 \%$ (productor 10 ) hasta $63,8 \%$ (productor 5). Estas diferencias son producto del número de animales que se reponen a lo largo del año productivo y del precio de compra de estos animales.

El segundo ítem importante en la estructura de costos es la alimentación, que en promedio representa el 19,46\% del total de costos, con un rango entre $10,61 \%$ (productor 9 ) y $27,23 \%$ (productor 2 ). Estas diferencias porcentuales se deben a los distintos sistemas productivos y de alimentación existentes. De los 11 productores, no todos incluyen en sus dietas ensilajes o concentrados para los animales en producción, lo que influye en la productividad y en los costos de producción. Además, para la crianza de terneros no todos los productores utilizan sustituto lácteo o concentrados de iniciación, lo que también influye en los costos de producción.

En el tercer lugar de incidencia se encuentran los costos de personal, que constituyen en promedio $14,36 \%$ de los costos totales. Los valores van desde $21,88 \%$ (productor 10) hasta $8,96 \%$ (productor 6), diferencias que podrían explicarse debido a que no todos los productores mantienen un número equivalente similar de personas de trabajo continuo u ocasional durante el periodo agrícola. Además, muchos de los productores administran su predio y realizan actividades agropecuarias por lo que no deben remunerar esos cargos, disminuyendo así sus costos de mano de obra.

Lerdón y Aspe (2000), en una investigación realizada con 13 empresas lecheras de la localidad de Panguipulli, encontraron valores similares a este estudio en la estructura de costos. Los mayores valores corresponden a la alimentación de ganado, reposición de animales, gastos de personal y gastos en fertilizantes y abonos, que en conjunto representan

Tabla 9. Margen total explotaciones.

\begin{tabular}{lccc}
\hline Productor & Margen explotación $(\$)$ & Ha & Margen explotación/Ha (\$/AÑ) \\
\hline 1 & 20.549 .564 & 90 & 228.328 \\
2 & 28.704 .872 & 117,5 & 244.297 \\
3 & -7.397 .920 & 39,7 & -186.346 \\
4 & 59.066 .792 & 81 & 729.220 \\
5 & 13.662 .587 & 146 & 93.579 \\
6 & 539.400 & 37,5 & 14.384 \\
7 & 1.906 .981 & 42 & 45.404 \\
8 & 28.814 .569 & 140 & 205.818 \\
9 & -845.219 & 42 & -20.124 \\
10 & 18.507 .889 & 190 & 97.410 \\
11 & 7.602 .316 & 120 & 63.353 \\
TOTAL & 171.111 .831 & 1.046 & 1.515 .324 \\
PROMEDIO & 15.555 .621 & 95 & 137.757 \\
\hline
\end{tabular}


Tabla 10. Estructura de costos.

\begin{tabular}{|c|c|c|c|c|c|c|c|c|c|c|c|c|}
\hline Costos $(\%) /$ Productor $\left(\mathrm{N}^{\circ}\right)$ & 1 & 2 & 3 & 4 & 5 & 6 & 7 & 8 & 9 & 10 & 11 & $\begin{array}{c}\text { Promedio } \\
(\%)\end{array}$ \\
\hline Materias primas e insumos & 0,14 & 0,83 & 0 & 0,63 & 0 & 0 & 0 & 1,03 & 2,15 & 1,024 & 1,15 & 0,63 \\
\hline Fertilizantes y abonos & 15 & 6,94 & 22,32 & 7,67 & 10,28 & 6,22 & 1,71 & 4,56 & 12,28 & 8,94 & 9,34 & 9,57 \\
\hline Semillas y plantas & 1,41 & 0,87 & 0 & 0,69 & 0,62 & 0 & 0 & 1,41 & 8,51 & 1,02 & 1,76 & 1,48 \\
\hline Agroquímicos & 0,36 & 0,51 & 0,16 & 0,16 & 0,23 & 0 & 0 & 0,78 & 0,54 & 6,58 & 0,55 & 0,90 \\
\hline Alimentos de ganado & 16,59 & 27,23 & 21,96 & 21,96 & 16,9 & 10,98 & 19,13 & 24,74 & 10,61 & 23,34 & 20,65 & 19,46 \\
\hline Productos veterinarios & 0,34 & 1,38 & 0,28 & 1,39 & 0,77 & 0,3 & 0,64 & 0,41 & 0,123 & 2 & 0,76 & 0,76 \\
\hline Combustibles y lubricantes & 2,72 & 1,59 & 2,83 & 3,26 & 0,92 & 1,39 & 1,19 & 0,68 & 3,19 & 6,29 & 5,34 & 2,67 \\
\hline Reposición de animales & 44,6 & 37 & 26,81 & 43,4 & 63,8 & 35,98 & 56,7 & 38,36 & 31,64 & 18,54 & 24,47 & 38,30 \\
\hline Personal & 13,86 & 17,88 & 9,11 & 12,82 & 2,91 & 8,96 & 13,74 & 17,2 & 20,1 & 21,88 & 19,48 & 14,36 \\
\hline Tasa e impuestos & 1,16 & 0 & 0 & 0 & 0,62 & 6,97 & 0,43 & 0,07 & 0 & 1,54 & 0 & 0,98 \\
\hline Arriendos & 0,85 & 1,76 & 0 & 0,59 & 1,51 & 3,87 & 3,32 & 4,38 & 4 & 1,92 & 10,1 & 2,94 \\
\hline Mantención y reparaciones & 0 & 0,84 & 15,22 & 3,96 & 0 & 17,42 & 1,21 & 1,05 & 2,47 & 0,76 & 0,86 & 3,98 \\
\hline Asesorías & 0 & 0,11 & 0,15 & 0,39 & 0 & 0,34 & 0,4 & 0 & 1,85 & 0 & 0,72 & 0,36 \\
\hline Honorarios & 0,34 & 0,71 & 0,188 & 0,18 & 0,07 & 0,58 & 0,19 & 0,15 & 0,49 & 0,6 & 0,86 & 0,40 \\
\hline Transportes y fletes & 1,1 & 0 & 0 & 0 & 0,25 & 0 & 0 & 0,31 & 0 & 1,93 & 0 & 0,33 \\
\hline Depreciaciones & 0 & 0 & 0 & 0 & 0 & 3 & 0,91 & 0 & 0 & 0 & 0 & 0,36 \\
\hline Teléfono & 0 & 0,7 & 0,36 & 0,8 & 0,62 & 0,48 & 0,29 & 0,07 & 0,123 & 0,256 & 1,44 & 0,47 \\
\hline Electricidad & 0 & 2,08 & 0,68 & 1,6 & 0,42 & 1,45 & 0,19 & 0,86 & 0,123 & 3,68 & 2,88 & 1,27 \\
\hline Inseminación & 0 & 0 & 0 & 0 & 0 & 0 & 0 & 0,25 & 0 & 0 & 0 & 0,02 \\
\hline Otros & 1,63 & 0 & 0 & 0,9 & 0 & 2,18 & 0,1 & 3,27 & 2,01 & 0,01 & 0,12 & 0,93 \\
\hline TOTAL & 100 & 100 & 100 & 100 & 100 & 100 & 100 & 100 & 100 & 100 & 100 & 100 \\
\hline
\end{tabular}

$64 \%$ de los costos totales, situación que se repite en la mayoría de las explotaciones lecheras. En este estudio, los ítems recién mencionados representan en su conjunto $81,69 \%$ del total de los costos.

Lerdón y Aspe (2000) observaron también que las depreciaciones representaban el cuarto ítem relevante en la estructura de costos, con un promedio de $6 \%$ de los costos totales.

\section{Estructura de ingresos}

En la Tabla 11 se puede observar que del total de ingresos generados durante el ciclo productivo, el más alto corresponde a la producción y comercialización de leche, que en promedio representa 19,36\% del total y que varía entre $0 \%$ para aquellos productores que no poseen lechería y $43,53 \%$ que recae en el productor 11. Este caso, junto con el productor 4, son los únicos que sobrepasan el $40 \%$ de los ingresos con su lechería, siendo uno de ellos (productor 4), el que tiene más vacas en ordeña (110 animales) y un mayor margen en la actividad (\$73.337.774).

El segundo ítem más alto de ingresos en los predios fue la producción y venta de novillos, que en promedio genera $14,96 \%$ de los ingresos totales, con valores que fluctúan entre $0 \%$ (productor 2, 3, 4, 6 y 9) y $74 \%$ (productor 5). Es necesario mencionar que este productor posee 171 novillos entre 2 y 3 años, siendo el más grande en este rubro.

La tercera fuente más alta de ingresos está representada por la producción de vaquillas, generando en promedio $13,31 \%$ de los ingresos de los agricultores. Existe gran variabilidad en este ítem, el que oscila entre $0 \%$ para aquellos productores que no se dedican a esta actividad, y 84,95\% para el productor 6, quien cría 54 vaquillas de 1 a 2 años. Este productor además tiene costos bajos en este rubro, alimentando solamente en base a pastoreo y heno de pradera. Por su parte, el productor 3 genera $28,21 \%$ de sus ingresos por producción de vaquillas y al igual que el productor 6 , la alimentación para 59 vaquillas es sobre la base de pastoreo y heno de pradera.

Finalmente, el cuarto ítem destacado corresponde a la venta de terneros, rubro que tienen en común todos los productores. En promedio, el 7,86\% de los ingresos totales proviene de la crianza de terneros y varía entre $19,16 \%$ (productor 10 ) y $0 \%$ (productores 6 y 9).

Lo anterior concuerda con Lerdon y Aspe (2000), quienes determinaron en su estudio en la localidad de Panguipulli, que el ítem de ingresos más alto corresponde a la venta de leche, representando $46 \%$ del ingreso promedio por hectárea. Este valor 
Tabla 11. Estructura de ingresos.

\begin{tabular}{|c|c|c|c|c|c|c|c|c|c|c|c|c|}
\hline Ingresos $(\%) /$ Productor $\left(\mathrm{N}^{\circ}\right)$ & 1 & 2 & 3 & 4 & 5 & 6 & 7 & 8 & 9 & 10 & 11 & $\begin{array}{c}\text { Promedio } \\
(\%)\end{array}$ \\
\hline Venta vaquillas preñadas & 7,72 & 11,9 & 0 & 21 & 0 & 0 & 0 & 6,92 & 0 & 0 & 0 & 4,32 \\
\hline Venta vaquillas cierre & 11,41 & 5,75 & 16,38 & 2,65 & 0 & 0 & 0 & 4,95 & 0 & 0 & 2,74 & 3,99 \\
\hline Venta vaquillas & 2,25 & 1,35 & 28,21 & 5,48 & 0 & 84,95 & 0 & 8,65 & 0 & 0 & 5,71 & 13,31 \\
\hline Venta de leche & 24 & 26,93 & 2,26 & 41,51 & 0 & 0 & 0,738 & 38 & 0 & 35,96 & 43,53 & 19,36 \\
\hline Venta vacas de desecho & 0,045 & 0,53 & 0,76 & 1,5 & 0 & 0 & 0 & 0,26 & 0 & 0 & 0 & 0,28 \\
\hline Venta de terneros & 8,78 & 6,77 & 1,92 & 4,2 & 5,51 & 0 & 15,16 & 10,88 & 0 & 19,16 & 14,12 & 7,86 \\
\hline Venta de terneras & 8,23 & 6,02 & 0,96 & 3,18 & 0 & 0 & 0 & 2,68 & 0 & 8,3 & 2,51 & 2,90 \\
\hline Venta de novillos & 3,53 & 0 & 0 & 0 & 74 & 0 & 73,15 & 2,76 & 0 & 5,38 & 5,7 & 14,96 \\
\hline Venta de leche a crianza & 2,59 & 3,5 & 2,26 & 0 & 0 & 0 & 0,74 & 3,83 & 0 & 3,33 & 5,24 & 1,95 \\
\hline Pastoreo & 3,83 & 4,23 & 21,94 & 1,98 & 10,13 & 2,89 & 9,48 & 4,1 & 6,28 & 11,88 & 8,41 & 7,74 \\
\hline Producción de ensilaje & 6,838 & 5,91 & 0 & 4,98 & 0 & 0 & 1,38 & 7,98 & 1,87 & 0 & 3,79 & 2,98 \\
\hline Producción de heno & 0 & 1,97 & 4,254 & 0,46 & 0 & 9,09 & 0 & 0,96 & 8,59 & 0 & 1,58 & 2,45 \\
\hline Producción de papas & 0 & 0 & 0 & 0 & 0 & 0 & 0 & 0 & 45,35 & 0 & 0 & 4,12 \\
\hline Producción de trigo & 0 & 0 & 0 & 0 & 0 & 0 & 0 & 0 & 0 & 10,15 & 0 & 0,92 \\
\hline Producción de avena & 8,96 & 0 & 0 & 0 & 2,06 & 0 & 0 & 2,35 & 4,01 & 0 & 0 & 1,58 \\
\hline Producción de paja & 1,034 & 0 & 0 & 0 & 0,56 & 0 & 0 & 0,51 & 0 & 0 & 0 & 0,19 \\
\hline Venta de frutillas & 0 & 0 & 0 & 0 & 0 & 0 & 0 & 0 & 24,05 & 0 & 0 & 2,19 \\
\hline Venta de ovinos & 0 & 0 & 0 & 0 & 7,81 & 3,03 & 0 & 0 & 0 & 0 & 0 & 0,99 \\
\hline Capitalización de acciones & 0 & 1,94 & 0 & 4,48 & 0 & 0 & 0 & 0 & 0 & 0 & 0 & 0,58 \\
\hline Reliquidación leche & 1,9 & 3,73 & 0 & 8,58 & 0 & 0 & 0 & 5 & 0 & 5,82 & 0 & 2,28 \\
\hline Ingresos varios & 8,82 & 20 & 22,5 & 0 & 0 & 0 & 0 & 0 & 0 & 0 & 6,66 & 5,23 \\
\hline TOTAL & 100 & 100 & 100 & 100 & 100 & 100 & 100 & 100 & 100 & 100 & 100 & 100 \\
\hline
\end{tabular}

alcanzó 23,77\% del ingreso promedio por hectárea en este estudio, seguido de la venta de novillos y la venta de vaquillas con valores de $15,15 \%$ y $14,85 \%$.

\section{Variables económico-financieras}

\section{Análisis de rentabilidad}

En la Tabla 12 se muestran las rentabilidades de los capitales propios y totales de las 11 explotaciones y sus promedios. Se puede observar una gran variabilidad en ambas rentabilidades, existiendo, como se verá más adelante, diferentes niveles de endeudamiento. El promedio es de $6,54 \%$ de rentabilidad para el capital propio y $5,81 \%$ para el capital total.

El $81,82 \%$ de los productores presenta rentabilidades de sus capitales propios y totales positivas, que fluctúan entre $2 \%$ y $23 \%$. En efecto, un alto porcentaje de los productores genera utilidades en su explotación, con diferencias en los niveles de inversión y financiamiento externo.

Lerdón y Aspe (2000) señalan que el valor de la rentabilidad promedio de los capitales propios calculada para los 13 predios lecheros analizados fue de $3,7 \%$, índice que se considera normal, ya que los valores observados en la Región, en explotaciones del mismo rubro, fluctúan desde valores negativos $(-5,6 \%)$ hasta valores máximos de $12 \%$. Por otra parte, la rentabilidad del capital total tuvo un promedio de 3,6\% para las 13 empresas lecheras, siendo este rango normal, por las razones antes mencionadas.

\section{Análisis de liquidez}

En la Tabla 13 se puede apreciar que $81,8 \%$ de los productores presentan un capital de operación positivo, esto indica que sus activos circulantes son superiores a las deudas contraídas a corto plazo.

Para este indicador de liquidez es necesario mencionar que el stock sirve también para cubrir necesidades diarias de la explotación, como los insumos, materias primas, etcétera, por lo que no es de plena seguridad que a partir de este activo circulante se puedan cancelar las deudas a corto plazo de la empresa en su totalidad, pudiendo ser necesario solicitar ampliaciones de plazo para cancelar las deudas contraídas en el corto plazo.

En este estudio, $81,8 \%$ de los predios presenta liquidez adecuada, lo que, según Lerdon (2000), refleja una buena capacidad de pago en relación con las fechas de vencimiento de las deudas a 
Tabla 12. Rentabilidad económica y financiera.

\begin{tabular}{lcc}
\hline PRODUCTOR & Rentabilidad capital propio $(\%)$ & Rentabilidad capital total $(\%)$ \\
\hline 1 & 18 & 18 \\
2 & 15 & 14 \\
3 & -6 & -6 \\
4 & 6 & 6 \\
5 & 3 & 3 \\
6 & 5 & 3 \\
7 & 2 & 2 \\
8 & 23 & 18 \\
9 & -1 & -1 \\
10 & 3 & 3 \\
11 & 4 & 4 \\
PROMEDIO & 6,54 & 5,81 \\
\hline
\end{tabular}

Tabla 13. Análisis de la liquidez.

\begin{tabular}{lr}
\hline Productor & Liquidez $(\$)$ \\
\hline 1 & 800.000 \\
2 & -2.700 .106 \\
3 & 13.100 .000 \\
4 & 4.000 .000 \\
5 & 27.800 .000 \\
6 & 2.000 .000 \\
7 & -24.000 .000 \\
8 & 2.500 .000 \\
9 & 0 \\
10 & 12.000 .000 \\
11 & 500.000 \\
TOTAL & 35.999 .894 \\
PROMEDIO & 3.272 .717 \\
\hline
\end{tabular}

corto plazo, siendo esto muy importante desde el punto de vista financiero.

\section{Análisis de solvencia}

La tasa de solvencia, medida como la relación porcentual entre el patrimonio y el pasivo total, debería ser superior al $60 \%$, ya que niveles más bajos podrían perjudicar la autonomía del productor (Lerdon, 2012). Se aprecia en la Tabla 14 , que el $91 \%$ de las explotaciones no presenta problemas de solvencia y por tanto tampoco de endeudamiento. De los 11 productores del GTT San Antonio, solo el productor 6 no alcanza el $60 \%$ de solvencia, por lo que sus capitales propios no logran financiar al menos un $60 \%$ del activo total, haciéndolo entonces vía créditos.

Estos resultados de solvencia indican que en general las empresas tienen un buen grado de independencia frente a sus acreedores, ya que la mayor parte de sus activos están siendo financiados por capitales propios.

\section{Análisis de autonomía financiera}

En la Tabla 15 se observa que 3 de las 4 empresas con valor calculado no presentan problemas de autonomía financiera, siendo la relación entre el patrimonio del empresario y sus deudas a mediano y largo plazo, adecuada. A diferencia del productor 6 en donde solo $17 \%$ de los capitales permanentes está representado por el patrimonio, correspondiendo $83 \%$ restante a deudas a mediano y largo plazo. El resto de los productores no tiene endeudamiento a más de un año plazo, por lo cual no es pertinente calcular este indicador.

\section{Relación entre rentabilidad y algunas variables sociales}

Las edades y el nivel de estudios de los productores se presentan en la Tabla 16, relacionándose estas variables con la rentabilidad de los capitales propios y totales de cada productor. Por tratarse de un estudio de casos, se presentan los resultados de las empresas sin homologación desde el punto de vista de los costos de oportunidad de la tierra, trabajo y capital, debiendo en el análisis tenerse presente que algunos predios analizados son propios y otros arrendados.

La edad promedio de los productores es de 49 años con un rango de 39 a los 67 años. Respecto del nivel de estudios, un productor tiene educación básica completa y el resto distintos grados de educación técnica y universitaria.

La rentabilidad del capital propio fluctúa entre $-6 \%$ y $23 \%$, con un promedio de $6,54 \%$ y aquella referida al capital total presenta un rango de $-6 \%$ a $18 \%$, con un promedio de $5,81 \%$. 
Tabla 14. Análisis de la solvencia.

\begin{tabular}{lcc}
\hline Productor & Tasa de solvencia $(\%)$ & Grado de endeudamiento $(\%)$ \\
\hline 1 & 100 & 0 \\
2 & 92 & 8 \\
3 & 99 & 1 \\
4 & 100 & 0 \\
5 & 100 & 0 \\
6 & 15 & 85 \\
7 & 81 & 19 \\
8 & 81 & 19 \\
9 & 100 & 0 \\
10 & 100 & 0 \\
11 & 100 & 0 \\
TOTAL & 968 & 132 \\
PROMEDIO & 88 & 12 \\
\hline
\end{tabular}

Tabla 15. Análisis de la autonomía financiera.

\begin{tabular}{lc}
\hline Productor & Autonomía financiera (\%) \\
\hline 1 & - \\
2 & 1554 \\
3 & - \\
4 & - \\
5 & - \\
6 & 17 \\
7 & 435 \\
8 & 425 \\
9 & - \\
10 & - \\
11 & - \\
TOTAL & 2431 \\
PROMEDIO & 607.8 \\
\hline
\end{tabular}

Los productores 1,2 y 8 alcanzan rentabilidades mayores y los tres tienen niveles de estudios técnicos. Un denominador común de estos tres productores es que arriendan tierras para producir, teniendo solo uno de ellos además suelo propio, por lo que el nivel de inversión es menor, lo que influye en la rentabilidad. Los productores 3 y 9 , que generan rentabilidades negativas, se caracterizan por ser jóvenes (43 y 39 años) y tienen estudios técnicos y universitarios incompletos. Cabe destacar que los productores 5, 6, 10 y 11 tienen mejores niveles académicos, sin embargo generan rentabilidades del capital propio más bajo que el promedio. Por otro lado, el productor 4 solo tiene educación básica completa, es el de mayor edad del grupo (67 años) y su rentabilidad del capital total es mayor al promedio. Esto se explicaría por la experiencia y oficio de este productor, con conocimientos adquiridos en muchos años de trabajo.

\section{Conclusiones}

Las 11 explotaciones en estudio, que en conjunto conforman el Grupo de Transferencia Tecnológica San Antonio, se encuentran dentro de los límites de la Región de Los Ríos, un porcentaje superior en

Tabla 16. Variables sociales y rentabilidad.

\begin{tabular}{|c|c|c|c|c|}
\hline Productor & Edad & Nivel de estudios & $\mathrm{RCP}(\%)$ & $\operatorname{RCT}(\%)$ \\
\hline 1 & 43 & técnica & 18 & 18 \\
\hline 2 & 63 & técnica agrícola & 15 & 14 \\
\hline 3 & 43 & técnica incompleta & -6 & -6 \\
\hline 4 & 67 & básica completa & 6 & 6 \\
\hline 5 & 54 & universitaria completa & 3 & 3 \\
\hline 6 & 62 & técnica profesional & 5 & 3 \\
\hline 7 & 45 & técnica incompleta & 2 & 2 \\
\hline 8 & 40 & técnica superior & 23 & 18 \\
\hline 9 & 39 & universitaria incompleta & -1 & -1 \\
\hline 10 & 46 & técnica profesional & 3 & 3 \\
\hline 11 & 41 & técnica superior & 4 & 4 \\
\hline PROMEDIO & 49 & estudios técnicos & 6,54 & 5,81 \\
\hline
\end{tabular}


la comuna de Paillaco en la Provincia de Valdivia y los predios restantes en las comunas de Futrono y Río Bueno.

Las inversiones más importantes están representadas por el suelo agrícola de los productores $(48,0 \%)$, el valor de las construcciones específicas y no específicas de los predios $(13,9 \%)$, las maquinarias y equipos de lechería o equipos no específicos $(8,6 \%)$ y a las vacas en producción de leche $(6,2 \%)$.

En el balance inicial de los productores, el promedio de los activos inmovilizados fue de $87,5 \%$ y de los circulantes de $12,5 \%$. Los pasivos no exigibles alcanzan un promedio de $88,1 \%$ y los pasivos exigibles $11,9 \%$, cifras que se asemejan a estudios realizados anteriormente.

La mayoría de los productores no arrienda suelo para sus actividades agropecuarias, utilizando suelo propio, lo que representa una fortaleza desde el punto de vista de su patrimonio.

Los márgenes directos unitarios del rubro de lechería tienen relación con el número de vacas en ordeña, fluctuando este entre 12 y 110 vacas en producción, y los márgenes totales del rubro entre -\$ 5.876.9691 y \$ 73.337.774.

Los márgenes directos unitarios del rubro de carne tienen relación con el número de animales en crianza, fluctuando este entre 11 y 143 terneros y los márgenes totales del rubro por ternero entre $\$-58.909$ y $\$ 209.889$.

Los beneficios netos en el rubro de crianza de vaquillas y terneros son similares a los de lechería, generándose una diferencia positiva entre los productores con mayor número de animales. Para esta actividad, también influye significativamente la alimentación del rebaño y los costos en productos veterinarios.

En promedio, los agricultores del GTT poseen 95,01 hectáreas de superficie y de estas $59,9 \%$ corresponden a praderas. Del total de las hectáreas de praderas destinadas a la producción, $71,39 \%$ son praderas naturales, $21,88 \%$ praderas mejoradas y $6,73 \%$ restante, praderas regeneradas o establecidas.
Los costos directos más importantes están representados por la reposición de animales, alimentación de ganado, salario por mano de obra y el costo de fertilizantes y enmiendas, que en promedio representan un $81,69 \%$ del costo total.

De los ingresos generados en los 11 predios, el $55,49 \%$ proviene de la comercialización de leche, venta de novillos, producción de vaquillas y terneros.

En general, el grupo GTT genera rentabilidades positivas ( $82 \%$ de las explotaciones), con un rango de $-6 \%$ y $23 \%$ para la rentabilidad del capital propio y $-6 \%$ a $18 \%$ para la rentabilidad del capital total, con promedios de $6,5 \%$ y $5,8 \%$ respectivamente.

Las rentabilidades del capital propio son mayores en el rubro lechería que en el de carne, con promedios de $9 \%$ y $2,3 \%$, respectivamente.

Los indicadores financieros de liquidez y solvencia permiten apreciar el estado financiero de cada explotación en el transcurso de un periodo. El $81,8 \%$ de los productores posee liquidez positiva, es decir, se autofinancian con los ingresos que generan. Un $45,5 \%$ de los productores poseen algún grado de endeudamiento y $27,3 \%$ ha contraído deudas a mediano y largo plazo.

Respecto del endeudamiento, $55 \%$ de los productores no declara deudas y para $45 \%$ restante el grado de endeudamiento fluctúa entre $1 \%$ y $85 \%$, con un promedio para el total de productores de $12 \%$.

En general, el bajo nivel de endeudamiento de estos productores representa una fortaleza y autonomía frente a los acreedores, teniendo la posibilidad de optar a créditos en mejores condiciones.

De las 11 explotaciones analizadas, $82 \%$ genera márgenes totales positivos, mientras que $18 \%$ obtiene márgenes totales negativos; esto permite que la mayor parte del GTT pueda financiar sus costos operacionales y de estructura durante el periodo y además cancelar impuestos e intereses por créditos recibidos.

Los niveles de estudio de los productores analizados no tienen incidencia en la rentabilidad, ya que productores con niveles de estudios completos (técnicos o profesionales) generan rentabilidades menores al promedio analizado. 


\section{Literatura Citada}

Instituto de Promoción de la Carne Vacuna Argentina (IPVCA). 2013. Producción de carne bovina en el mercado Europeo. (En línea). Disponible en: http://www.ipcva.com.ar/ . Consultado: 7/mayo/2013.

Organización de las Naciones Unidas para la Agricultura y la Alimentación (FAO).

2012. Producción global de la leche. Producción y productos lácteos. (En línea) Disponible en: http://www.fao.org/ agriculture/dairy-gateway/produccion-lechera/es/\#. Uqm2S_TuLCY Consultado: 5/ diciembre/ 2013.

Oficina de Estudios y Políticas Agrarias (ODEPA).

2015a. Ministerio de Agricultura, Carne. Boletín de la Carne. Tendencias de producción, precios y comercio exterior. (En Línea). Disponible en: http://www.odepa.gob.cl//odepaweb/ servicios-informacion/Boletines/Boletin_de_carne_112013. pdf;jsessionid=242A7D36153B1B145113CA970E6D06C7 Consultado: 6/ abril/2015.

Oficina de Estudios y Políticas Agrarias (ODEPA).

2015b. Ministerio de Agricultura. Leche: Boletín de la leche. (En Línea). Disponible en: http://www.odepa.gob. cl/odepaweb/servicios-informacion/Lacteos/leche2012. pdf Consultado: 6/abril/2015.

Corporación de Fomento de la Producción (CORFO).

2013. Ministerio de Agricultura, Gobierno de Chile. (En línea). Disponible en: http://www.corfo.cl/programas-y-concursos/ programas/concurso-fortalecimiento-de-capital-humanoen-transferencia-tecnologica Consultado: 25/noviembre/ 2013.

Instituto de Investigaciones Agropecuarias (INIA). 2013. Grupos de Transferencia tecnológica (GTT), (en línea). Disponible en: www.inia.cl. Consultado: 25/mayo/2013

Lerdon, J. Rabanal, I. 1999. Análisis económico y financiero de 29 predios campesinos lecheros de Paillaco. Agro Sur, 27 (2): 145-166.

Lerdon, J. Aspe, $\mathrm{H}$.

2000. Análisis económico de 13 empresas lecheras de la localidad de Panguipulli, Chile. Estudio de casos. Agro Sur, 28 (1): 1-12.

Lerdon, $\mathrm{J}$.

2012. Análisis financiero de empresas agrícolas. Universidad Austral de Chile, Facultad de Ciencias Agrarias, Instituto de Economía Agraria, Valdivia. 101 p.

Lopez, I., Balocchi, O., Lailhacar, P. Oyarzún, C.

1997. Caracterización de sitios de crecimiento de seis especies pratenses nativas y naturalizadas del dominio húmedo de chile. Agro Sur, 25(1): 62-80.

Pérez, M. A.; Peña, F.A.; Benítez, M.J.

2011. Sales minerales en la ganadería de leche bovina. Rev. Sist. Prod. Agroecol., 2(2):65-80. 